\title{
Maillard reaction induces changes in saccharides and amino acids during stir-baking of areca nuts
}

\author{
Mei-Bian Hu, Wei Peng, Yu-Jie Liu, Dan Yan, Xi Chen, Chun-Jie Wu* \\ College of Pharmacy, Chengdu University of Traditional Chinese Medicine, No. 1166 Liutai Avenue, Chengdu 610075, PR \\ China \\ *For correspondence: Email: wucjcdtcm@163.com; Tel/Fax: +86-028-61801001
}

\begin{abstract}
Purpose: To investigate changes in saccharides and amino acids induced by Maillard reaction (MR) during stir-baking of areca nuts $(A N)$.

Methods: The $\mathrm{pH}$ of aqueous extracts of $\mathrm{AN}$ and charred $\mathrm{AN}$ (CAN) were measured by a $\mathrm{pH}$ meter, and their absorbances at $420 \mathrm{~nm}$ were read in an ultraviolet-visible (UV-VIS) spectrophotometer. Changes in saccharides and amino acids were evaluated by high performance liquid chromatography (HPLC) and automated amino acid analyzer, respectively.

Results: The $\mathrm{pH}$ of AN (5.85 \pm 0.09$)$ was lower than that of CAN (5.25 \pm 0.04$)$. Stir-baking significantly increased the $A_{420}$ value of $A N(0.32 \pm 0.01$ to $0.62 \pm 0.02$ (CAN). In addition, the contents of reducing saccharides (fructose and glucose) and free amino acids (serine, lysine, arginine and proline) were significantly decreased in the stir-baked CAN compared with AN.

Conclusion: MR, during stir-baking of AN, decreases levels of free amino acids and reducing sugars due probably to the reaction between saccharides and amino acids.
\end{abstract}

Keywords: Areca nut, Stir-baking, Maillard reaction, Reducing sugars, Free amino acids

Tropical Journal of Pharmaceutical Research is indexed by Science Citation Index (SciSearch), Scopus, International Pharmaceutical Abstract, Chemical Abstracts, Embase, Index Copernicus, EBSCO, African Index Medicus, JournalSeek, Journal Citation Reports/Science Edition, Directory of Open Access Journals (DOAJ), African Journal Online, Bioline International, Open-J-Gate and Pharmacy Abstracts

\section{INTRODUCTION}

MR, also called non-enzymatic browning reaction, is one of the main reactions involved in food processing. The reaction involves the amino groups of amino acids, proteins (or any nitrogenous compound), and carbonyl groups of reducing sugars, aldehydes or ketones [1,2]. Previous studies revealed that MR can result in formation of some new compounds such as 5hydroxymethylfurfural (5- HMF), methyl maltol, etc and MR products contribute to flavor formation, as well as antioxidant and antimicrobial effects of processed foods $[3,4]$.

AN (Areca catechu LINN) is widely distributed in Southern and Southeast Asia including China,
India and Indonesia [5]. It is reported that over 400 million people daily chew betel quid which is prepared from the immature fruits of areca nut, betel leaf and lime in some Asia areas, especially in Taipei, China [6]. AN is also used as an important traditional herbal medicine in China for the treatment of parasitic diseases, dyspepsia, abdominal distension, abdominal pain and diarrhea [5].

Prior to clinical usage, AN is traditionally processed by charring it to a dark brown color through the process of stir-baking, so as to enhance its efficacy and reduce its toxicity $[7,8]$. Although previous studies showed that MR is involved in the processing of AN, not much is known about changes in saccharides and amino 
acids during this process. The present study compared saccharide and amino acid contents of AN and its processed product, in order to determine the mechanism involved in the MR.

\section{EXPERIMENTAL}

\section{Chemicals and reagents}

Areca nuts were purchased from the Neautus Chinese Herbal Pieces Ltd. Co. (Chengdu, China), and were identified by Prof Chun-Jie Wu (College of Pharmacy, Chengdu University of Traditional Chinese Medicine, Chengdu, China). A voucher specimen (sAN-20160117) deposited in College of Pharmacy, Chengdu University of Traditional Chinese Medicine (Chengdu, China). All standards in the study were purchased from the National Institute for the Control of Pharmaceutical and Biological Products (Beijing, China). All other chemicals used in this study were analytical reagent grade.

\section{Preparation of samples and standards}

Dried AN was powdered and exhaustively extracted with $80 \%$ ethanol for $3 \mathrm{~h}$ to remove colored materials. After filtration, the residue was air-dried and extracted with distilled water by refluxing. The extract was left to cool at room temperature and filtered for use in HPLC analysis. Solutions of standard sugars (fructose, glucose, sucrose, raffinose, and stachyose (1 $\mathrm{mg} / \mathrm{mL})$ ) were prepared in distilled water.

\section{Determination of $\mathrm{pH}$ and $\mathrm{A}_{420}$}

$\mathrm{pH}$ values of $\mathrm{AN}$ and $\mathrm{CAN}$ extracts were measured using a $\mathrm{pH}$ meter (Leici, PHS-3C, Shanghai, China) calibrated with standard buffer solutions of $\mathrm{pH} 4.0$ and 10.0 .

A420 values of $\mathrm{AN}$ and CAN were measured according to the method described previously [9]. The samples were decocted with distilled water and filtered. The absorbance of the filtrate was measured at $420 \mathrm{~nm}$ in a TU-1901 UV - VIS spectrophotometer (Puxitongyong, Beijing, China).

\section{Determination of saccharide contents}

The aqueous extracts of the samples and the saccharide standard solutions were filtered through $0.45 \mu \mathrm{m}$ nylon filters before injecting into HPLC system (Agilent, 1260, USA). In this process, $10 \mu \mathrm{L}$ of each extract or standard was analyzed using a SepaxCarbomix Ca-NP column $(300 \mathrm{~mm} \times 7.8 \mathrm{~mm}, 10 \mu \mathrm{m})$ with an evaporative light-scattering detector (ELSD) (Alltech,
2000ES, USA).Ultra-pure water was used as the mobile phase at a flow rate of $0.3 \mathrm{~mL} / \mathrm{min}$, and the temperature of the column was set at $75^{\circ} \mathrm{C}$.

\section{Validation of the HPLC method}

Calibration curves of fructose, glucose, sucrose, raffinose, and stachyose were obtained by analysis of different injection volumes (each standard solution was analyzed in triplicate). The calibration curves were prepared by plotting peak area logarithm values against injection volume logarithm values for each saccharide. Linear regression analysis was then used to calculate the slope, intercept and correlation coefficient of each curve.

Precision tests were performed by injecting the same aqueous extract repeatedly 6 times. The peak areas of the five saccharide standards were obtained and their relative standard deviation (RSD) was calculated to assess the precision of the HPLC system.

Repeatability tests were assessed by analyzing aqueous extracts of 6 samples using the above procedure, and the RSD of peak area for each saccharide was calculated.

Stability tests were carried out by analyzing the same water extract every $4 \mathrm{~h}$ for $24 \mathrm{~h}$ using the same procedure as outlined above, and the RSD of peak area for each saccharide was calculated. For the recovery tests, selected samples were spiked with known amounts of fructose, glucose, raffinose, raffinose and stachyose, and analyzed by the same method. Mean recovery was calculated as in Eq 1.

Recovery $(\%)=\{(\mathrm{Aa}-\mathrm{Ai}) / \mathrm{As}\} \times 100$

where $\mathrm{Aa}, \mathrm{Ai}$ and $\mathrm{As}$ are measured amount, initial amount and spiked amount, respectively.

\section{Determination of amino acid contents}

The contents of free amino acids in AN and CAN were determined using a fully-automated amino acid analyzer (Hitachi, L-8900A, Tokyo, Japan). A calibration curve was obtained with standard amino acid mixture (Sigma, St. Louis, MO, USA) and qualitative analysis was performed based on retention time and peak area of standard compounds.

\section{Data analysis}

All the tests were carried out in triplicate, and the data are presented as mean \pm SD. Group comparison was performed by ANOVA (SPSS 
16.0). $P<0.05$ was considered statistically significant.

\section{RESULTS}

\section{Changes in $\mathrm{pH}$ and $\mathrm{A}_{420}$}

Results for $\mathrm{pH}$ and $\mathrm{A}_{420}$ are shown in Table 1. $\mathrm{pH}$ was significantly decreased $(p<0.05)$, whereas $\mathrm{A}_{420}$ value was significantly increased $(p<0.05)$ in CAN compared to AN.

\section{Validation of the HPLC method}

The HPLC method was validated for linearity, precision, repeatability, stability and recovery. The results of linearity test for the five sugars including calibration equation, coefficient of association $\left(R^{2}\right)$ and linearity range were shown in Table 2. The calibration equations for fructose, glucose, sucrose, raffinose, and stachyose were $y=1.9935 x+5.1398 ; y=1.1781 x+5.9556 ; y=$ $1.569 x+5.6098 ; y=1.3751 x+5.7466$ and $y=$ $1.3408 x+5.8366$, respectively. In addition, the results showed that the calibration equations presented a good linear relationship $\left(R^{2}>0.998\right)$, with linearity ranges of $2.04-10.20,1.92-9.60$, 2.08 - 10.40, $1.50-9.50$ and $10.00-25.00 \mathrm{ug}$, respectively.
The results of precision tests are shown in Table 3. The peak area RSD values of the five saccharides were $0.97,0.71,0.73,0.93$ and 0.81 , respectively. The results of precision tests indicated that HPLC system presented a good precision.

The results of repeatability tests, stability tests and recovery tests are shown in Table 3. RSD values of the five sugars were below 3 . The results demonstrate that the HPLC method of sugar determination exhibited good repeatability and accuracy. The RSDs of the peak areas were also below 3, which indicate that the aqueous extracts were stable for $24 \mathrm{~h}$.

\section{Changes in saccharide contents}

HPLC chromatograms of the standards and samples are shown in Figure 1, while the levels of fructose, glucose, sucrose, raffinose, and stachyose in AN and CAN are depicted in Table 2. The results show that fructose, glucose, sucrose, raffinose, and stachyose are the main reducing sugars in AN. However, the main reducing sugar in CAN is stachyose. The present study demonstrates that the contents of fructose, glucose, sucrose and raffinose decreased, whereas the content of stachyose increased after AN was processed to CAN by stir-baking.

Table 1: Results of $A_{420}$ and $\mathrm{pH}$ of AN (areca nut) and CAN (charred areca nut)

\begin{tabular}{lcc}
\hline Sample & pH & $\boldsymbol{A}_{\mathbf{4 2 0}}$ \\
\hline Areca nut & $5.85 \pm 0.09$ & $0.32 \pm 0.01$ \\
Charred areca nut & $5.25 \pm 0.04^{*}$ & $0.62 \pm 0.02^{*}$ \\
\hline${ }^{*} p<0.05$ compared with areca nut & &
\end{tabular}

Table 2: Calibration equation, coefficient of association $\left(R^{2}\right)$, linearity range and saccharides contents in $A N$ and CAN

\begin{tabular}{llcccc}
\hline Content & Calibration equation & $\boldsymbol{R}^{\mathbf{2}}$ & $\begin{array}{c}\text { Linearity range } \\
(\mathbf{u g})\end{array}$ & $\begin{array}{c}\text { Areca nut } \\
(\mathbf{m g} / \mathbf{g})\end{array}$ & $\begin{array}{c}\text { Charred areca } \\
\text { nut }(\mathbf{m g} / \mathbf{g})\end{array}$ \\
\hline Fructose & $Y=2.0716 X+5.1026$ & 0.9987 & $2.04-10.20$ & $5.58 \pm 0.18$ & - \\
Glucose & $Y=1.183 X+5.957$ & 0.9988 & $1.92-9.60$ & $5.87 \pm 0.07$ & -- \\
Sucrose & $Y=1.569 X+5.6098$ & 0.9986 & $2.08-10.40$ & $7.63 \pm 0.16$ & - \\
Raffinose & $Y=1.3751 X+5.7466$ & 0.9989 & $1.50-9.50$ & $1.45 \pm 0.10$ & -- \\
Stachyose & $Y=1.3429 X+5.8315$ & 0.9989 & $10.00-25.00$ & $15.73 \pm 0.18$ & $18.47 \pm 0.13$ \\
\hline
\end{tabular}

Table 3: Precision, repeatability, stability, and recovery data

\begin{tabular}{lccccc}
\hline Content & $\begin{array}{c}\text { Precision } \\
\text { RSD (\%) }\end{array}$ & $\begin{array}{c}\text { Repeatability } \\
\text { RSD (\%) }\end{array}$ & $\begin{array}{c}\text { Stability } \\
\text { RSD (\%) }\end{array}$ & Mean recovery (\%) \\
\hline Fructose & 0.97 & 0.71 & 0.38 & 1.24 & 100.12 \\
Glucose & 0.71 & 1.44 & 1.05 & 1.06 & 98.93 \\
Sucrose & 0.73 & 1.11 & 1.05 & 1.22 & 99.51 \\
Raffinose & 0.93 & 0.75 & 0.67 & 1.18 & 98.85 \\
Stachyose & 0.81 & 0.89 & 0.74 & 0.49 & 99.61 \\
\hline
\end{tabular}



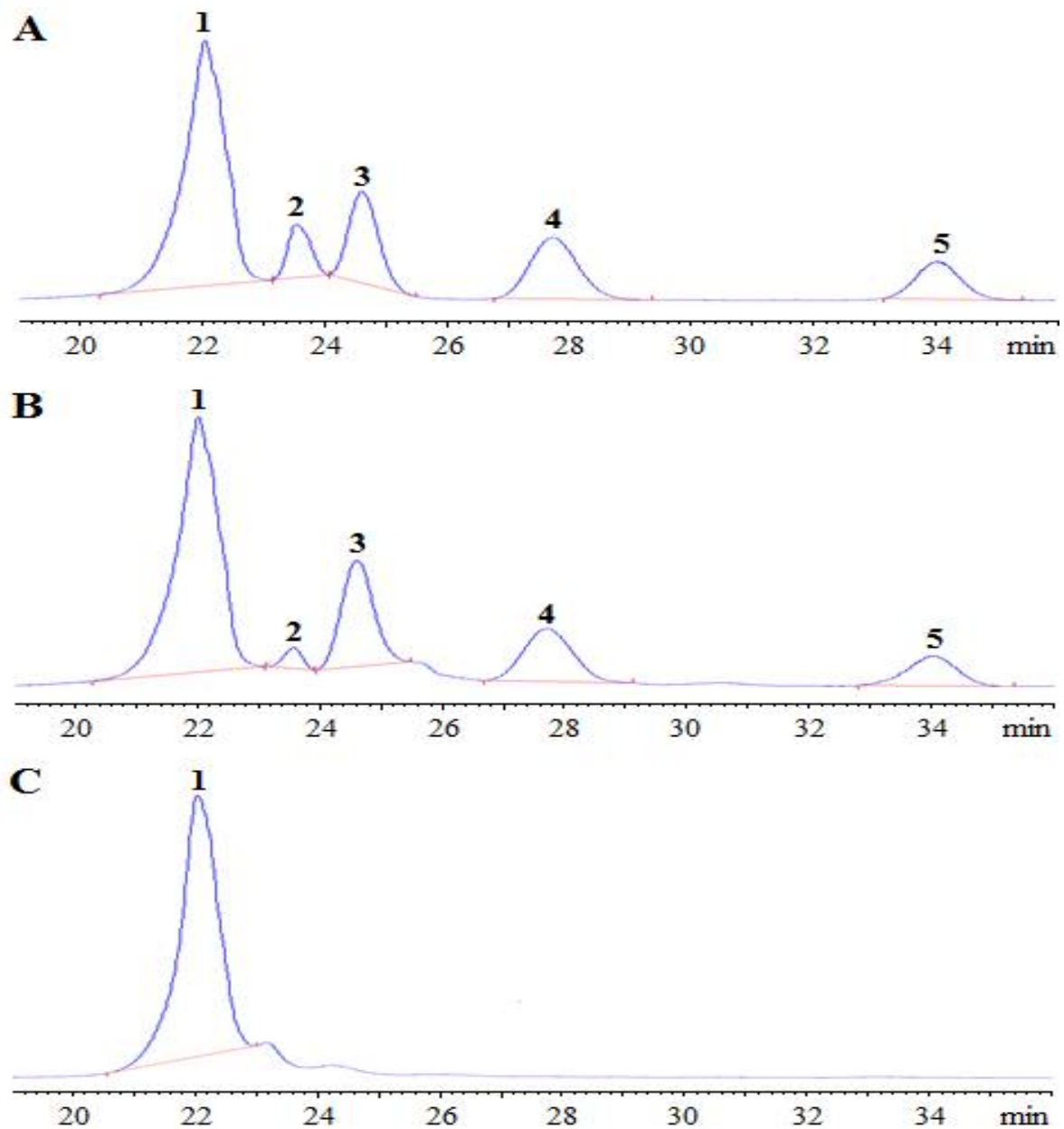

Figure 1: HPLC chromatograms of sugar standards and samples (AN \& CAN). A-C represents saccharide standards. 1-5 represent stachyose, raffinose, sucrose, glucose, and fructose, respectively

Table 4: Amino acid contents of areca and charred areca nuts

\begin{tabular}{lccc}
\hline Compound & Areca nut (\%) & Charred areca nut(\%) & Reduction (\%) \\
\hline aspartic acid & $0.46 \pm 0.03$ & $0.44 \pm 0.05$ & 0.02 \\
Threonine & $0.16 \pm 0.02$ & $0.13 \pm 0.02$ & 0.03 \\
Serine & $0.29 \pm 0.03$ & $0.14 \pm 0.04^{*}$ & 0.15 \\
Glutamate & $1.31 \pm 0.09$ & $1.32 \pm 0.07$ & -0.01 \\
Glycine & $0.24 \pm 0.05$ & $0.23 \pm 0.04$ & 0.01 \\
Alanine & $0.23 \pm 0.05$ & $0.22 \pm 0.04$ & 0.01 \\
Cysteine & $0.26 \pm 0.04$ & $0.18 \pm 0.03$ & 0.08 \\
valine & $0.40 \pm 0.05$ & $0.36 \pm 0.04$ & 0.04 \\
Methionine & $0.07 \pm 0.04$ & $0.08 \pm 0.03$ & -0.01 \\
Isoleucine & $0.26 \pm 0.03$ & $0.24 \pm 0.04$ & 0.02 \\
Leucine & $0.38 \pm 0.04$ & $0.39 \pm 0.02$ & -0.01 \\
Tyrosine & $0.15 \pm 0.03$ & $0.13 \pm 0.02$ & 0.02 \\
Phenylalanine & $0.33 \pm 0.04$ & $0.33 \pm 0.04$ & 0.00 \\
Lysine & $0.33 \pm 0.05$ & $0.13 \pm 0.04^{*}$ & 0.20 \\
histidine & $0.13 \pm 0.04$ & $0.08 \pm 0.02$ & 0.05 \\
Arginine & $0.83 \pm 0.11$ & $0.47 \pm 0.04^{*}$ & 0.36 \\
Proline & $0.29 \pm 0.05$ & $0.13 \pm 0.03^{*}$ & 0.16 \\
Total amino & 6.11 & 5.00 & 1.11 \\
acid & & &
\end{tabular}

\section{Changes in free amino acids}

The results for levels of free amino acids in AN and CAN are shown in Table 4. It shows that 17 amino acids were detected in AN and CAN. The content of free amino acids decreased in CAN, when compared to AN. In addition, serine, lysine, arginine and proline were significantly decreased after AN was processed to CAN. 


\section{DISCUSSION}

The saccharide and free amino acid changes were determined in $\mathrm{AN}$ and its processed products (CAN) in the present research, and the results showed that MR during the processing of AN to CAN might be related to changes in levels of reducing sugars (fructose and glucose) and free amino acids (serine, lysine, arginine and proline).

MR occurs in three stages: initial, intermediate and final stages. The initial stage involves formation of sugar amine and Amadori rearrangement, a process which generates colorless products. During the intermediate stage, the color of the reaction products is weak, or yellow, with strong absorption in the nearultraviolet region. In the final stage, highly colored compounds are generated from aldol condensation and aldehyde-amide polymerization [2].

It has been reported that $\mathrm{pH}$ decreases rapidly with heating time during MRs [10]. MR occurs between free amino groups of peptides or amino acids and carbonyl groups of reducing sugars, resulting in acidic $\mathrm{pH}$ due to consumption of amino groups [11], leading to rapid decrease in $\mathrm{pH}$. Furthermore, the reactants, intermediates and end-products of MR, such as formic acid, acetic acid and glyoxal, being acidic, also result in decreases in $\mathrm{pH}$ [12]. In addition, $\mathrm{A}_{420}$ is considered an indicator of the final stage of MR, which can be used as index of browning intensity due to formation of brown pigments $[12,13]$. Indeed UV absorbance at $420 \mathrm{~nm}$ gives an indication of the intensity of the browning process during MR. In the present study, compared to the $\mathrm{AN}, \mathrm{pH}$ value decreased whereas $\mathrm{A}_{420}$ value increased in CAN, indicating that MR occurred during the process stir-backing.

MR is a complex reaction initiated between carbonyl groups of reducing sugars and free amino groups [14]. The main reducing sugars that participate in MR are disaccharides (sucrose or lactose), pentoses (xylose, ribose and arabinose) and hexoses (glucose, fructose, mannose and galactose) [15].The concentration and types of sugar influence the type of MR products [15]. Specific combinations of amino acids and reducing sugars can produce a variety of specific flavors [14]. Many studies have reported that serine, lysine, arginine and proline react with fructose or glucose to generate volatile compounds with aroma, and their reaction mechanisms are already elucidated [16-19]. In the present study, the significant decreases in contents of reducing sugars (fructose and glucose) and free amino acids (serine, lysine, arginine and proline) in CAN, relative to $\mathrm{AN}$ demonstrate that in the stir-baking process, the mechanism of MR is related to decreases in amounts of reducing sugars (fructose and glucose) and free amino acids (serine, lysine, arginine and proline). The HPLC method used for detecting the sugar contents was validated for linearity, precision, repeatability, stability and recovery. The results revealed that the method exhibited good linearity, precision, repeatability, stability and accuracy, indicating that it was very suitable for determination of saccharide contents of $\mathrm{AN}$ and CAN.

\section{CONCLUSION}

The results of the present study indicate that MR occurs during the processing of $\mathrm{AN}$ to CAN, the underlying mechanism of which may be related to changes in reducing sugars and amino acids.

\section{DECLARATIONS}

\section{Acknowledgement}

This work was supported by the National Natural Science Foundation of China (no. 81373969).

\section{Conflict of Interest}

No conflict of interest associated with this work.

\section{Contribution of Authors}

The authors declare that this work was done by the authors named in this article and all liabilities pertaining to claims relating to the content of this article will be borne by them.

\section{REFERENCES}

1. Hodge JE. Dehydrated foods, chemistry of browning reactions in model systems. J Agr Food Chem 1953; 1: 938-943.

2. Gullón B, Montenegro MI, Ruiz-Matute Al, CardelleCobas A, Corzo N, Pintado ME. Synthesis, optimization and structural characterization of a chitosan-glucose derivative obtained by the Maillard reaction. Carbohydr Polym 2016; 137: 382-389.

3. Chevalier F, Chobert JM, Genot C, Haertle T. Scavenging of free radicals, antimicrobial and cytotoxic activities of the Maillard reaction products of beta lactoglobulin glycated with several sugars. J Agr Food Chem, 2001; 49: 5031-5038.

4. Liu Z, Chao Z, Liu Y, Song Z, Lu A. Maillard reaction involving in the steaming process of root of Polygonummultiflorum. Planta Med 2009; 75: 84. 
5. Peng $W$, Liu $Y J$, Wu $N$, Sun $T$, He $X Y$, Gao $Y X, W u$ CJ.Areca catechu L. (Arecaceae): $A$ review of its traditional uses, botany, phytochemistry, pharmacology and toxicology. J Ethnopharmacol 2015; 164: 340-356.

6. Heatubun $C D$, Dransfield J, Flynn T, Tjitrosoedirdjo SS, Mogea JP, Baker W. A monograph of the betel nut palms (Areca: Arecaceae) of East Malesia. Bot J Linn Soc 2012; 168: 147-173.

7. Xu M, Yang SL, Peng W, Liu YJ, Xie DS, Li XY, WU CJ. A Novel Method for the Discrimination of Semen Arecae and Its Processed Products by Using Computer Vision, Electronic Nose, and Electronic Tongue. Evid-based Compl. Alt 2015; 753942.

8. Editorial Committee of Chinese Pharmacopoeia. 2015. Chinese Pharmacopoeia (2010 ed.). vol. 1. China Medical Science and Technology Press: Beijing; pp 24, 342-343.

9. Luyun C, Dongmei L, Zhijian D, Ailing C, Hong L, Jianrong $L$. Change regularity of the characteristics of Maillard reaction products derived from xylose and Chinese shrimp waste hydrolysates. LWT-Food Sci Technol 2016; 65: 908-916.

10. Jiang ZM, Wang LZ, Che HX, Tian B. ().Effects of temperature and $\mathrm{pH}$ on angiotensin-I-converting enzyme inhibitory activity and physicochemical properties of bovine casein peptide in aqueous Maillard reaction system. LWT-Food Sci Technol, 2014; 59: 35-42.

11. Eric $K$, Raymond LV, Abbas S, Song $S Q$, Zhang $Y T$, Kingsley M. Temperature and cysteine addition effect on formation of sunflower hydrolysate Maillard reaction products and corresponding influence on sensory characteristics assessed by partial least square regression. Food ResInt2014; 57: 242-258.
12. Martins SI, Van Boekel MA. A kinetic model for the glucose/glycine Maillard reaction pathways. Food Chem2005; 90: 257-269.

13. Serpen A, Gokmen V. Evaluation of the Maillard reaction in potato crisps by acrylamide, antioxidant capacity and color. J Food Compos Anal2009; 22: 589-595.

14. Tang LW, Tian HY, Sun BG, Zhang J. Formation of Isovaleraldehyde in the Maillard Model Reaction System Consisting of Leucine and Reducing Sugar. Food Sci 2009; 30: 145-148.

15. Zhou YQ, He FY, Yang YT, Shi JL, Deng KW, Tang $Y$. Research situation of Maillard reaction and its influence on research methods for processing and preparation process of Chinese materia medica. Chin Trad Herb Drug 2014; 45: 125-130.

16. Yang J, Yang L, Gao T, Wu YQ, Cao LE. Study on Nonaqueous Phase Maillard Reaction of Glucose / Llysine Model Syste18m. Tobacco Chem 2011; (8): 5561.

17. Gao Q, Yuan DB, Yang JS, Li FF, Li YX, Wang CZ, Chen $J$. Effect of Combined Maillard Reaction Products in Fructose-lysine Model System and Pulsed Electric Field Sterilization on Banana Juice Quality. Mod Food Sci Tec 2015; 31: 220-226.

18. Deng Y. Comparison of Volatile Generation in Serine/Threonine/Glutamine-Ribose/Glucose/Fructose Model Systems. Food Industry 2010; (3): 58-61.

19. Zhou ZL, Xu ZQ, Zhou S, Wang H, Xu FF,Li Y, Zhong F. Formation and reaction pathway of caramel- like aroma compounds in solid state Maillard model system of reducing sugars and proline. Food Ferment Industr 2014; 40: 30-34. 